\title{
The frequency of vitamin D deficiency in Ordu and its relationship with chronic diseases
}

\author{
๑Harun Düğeroğlu, ๑Yasemin Kaya \\ Ordu University Training and Research Hospital, Faculty of Medicine, Department of Internal Medicine, Ordu, Turkey
}

Cite this article as: Düğeroğlu H, Kaya Y. The frequency of vitamin D deficiency in Ordu and its relationship with chronic diseases. Anatolian Curr Med J 2022; 4(1); 8-12.

\begin{abstract}
Aim: The aim of this study was to evaluate the frequency of vitamin D deficiency in adult patients admitted to our hospital in Ordu and the relationship between this deficiency and chronic diseases.

Material and Method: In our study, the vitamin D levels of 1432 patients aged 18 yeras and over who applied to the Internal Medicine outpatient clinic between 01.01.2019-31.12.2019 were retrospectively evaluated. Age, gender, chronic diseases were evaluated and vitamin D levels of the patients were measured. Patients with serum vitamin D level of $<20 \mathrm{ng} / \mathrm{ml}$ are in the vitamin D deficiency group; Patients between $21-30 \mathrm{ng} / \mathrm{ml}$ are in the vitamin D insufficiency group; Patients $>30 \mathrm{ng} / \mathrm{ml}$ were included in the normal vitamin D group.

Results: The study consisted of 1092 females (76.4\%) and 340 males (23.6\%). We found vitamin D deficiency and insufficiency in approximately $88.3 \%$ of the patients. In addition, serum vitamin D levels of female patients included in the study were found to be significantly lower than male patients $(\mathrm{p}=0.007)$. There were statistically significant differences between the groups in the number of patients included in the study who had a chronic disease and in the evaluation of their vitamin D levels (insufficient, deficient, normal $)(\mathrm{p}=0.021, \mathrm{p}=0.012, \mathrm{p}=0.047, \mathrm{p}=0.043, \mathrm{p}=0.032$, respectively).

Conclusion: With this study, a very high rate of vitamin D deficiency and insufficiency, such as $88.3 \%$, was found in Ordu. In addition, there was a significant relationship between vitamin D deficiency and chronic diseases in our study.
\end{abstract}

Keywords: Vitamin D deficiency, 25-hydroxy vitamin D, frequency, chronic diseases, mortality

\section{INTRODUCTION}

Vitamin D is among the fat-soluble vitamins (1). Vitamin $\mathrm{D}$ is a sterol that can be synthesized endogenously and is hormone precursors. Our skin, which is exposed to sunlight, has the ability to synthesize vitamin $\mathrm{D}$. There are two forms of vitamin D, vitamin D2 (ergocalciferol) and vitamin D3 (cholecalciferol). Of these, vitamin D3 type constitutes its endogenously synthesized form in the skin, and vitamin D2 type constitutes the form taken exogenously with food (2). The most important task of vitamin $\mathrm{D}$ is to regulate calcium and phosphorus metabolism and also to provide bone mineralization (3). Vitamin D deficiency causes osteomalacia, osteoporosis, and the risk of bone fractures in patients (4). Many studies have shown that severe vitamin D deficiency is due to insufficient exposure to sunlight, especially in winter months $(5,6)$. However, excessive use of sunscreen creams and insufficient intake of vitamin $\mathrm{D}$ with food also cause vitamin $\mathrm{D}$ deficiency
(7). Again, many studies have shown that vitamin D deficiency is associated with infections, cardiovascular diseases, multiple sclerosis, psychiatric disorders such as depression, diabetes, autoimmune diseases, even breast and colon cancers (8-11). In patients with chronic disease, either insufficient intake of vitamin $\mathrm{D}$ with food or the process of chronic disease may cause vitamin $\mathrm{D}$ deficiency by disrupting the metabolism of vitamin $\mathrm{D}$. In addition, drugs used in chronic diseases may impair vitamin D metabolism. Again, some studies have shown that vitamin $\mathrm{D}$ deficiency in patients with chronic diseases shortens the life span of the patients, increases mortality and causes serious complications in patients. They argued that the reason for this is the loss of anti-inflammatory, anti-oxidant and anti-ischemic properties of vitamin $\mathrm{D}$, which have positive effects on the body, in case of vitamin D deficiency $(12,13)$. 
The aim of our study was to evaluate the frequency of vitamin $\mathrm{D}$ deficiency in patients aged 18 years and over who applied to our hospital in Ordu, and to evaluate the relationship of vitamin $\mathrm{D}$ deficiency with chronic diseases in these patients. Thus, we think that early detection of vitamin D deficiency in patients with chronic diseases and adequate vitamin D replacement in these patients will have positive effects on the patient's response to treatment and mortality.

\section{MATERIAL AND METHOD}

The study was carried out with the permission of Ordu University Clinical Research Ethics Committee (Date: 29.03.2018, Decision no: 2018- 57). All procedures were carried out in accordance with the ethical rules and the principles of the Declaration of Helsinki.

Our study included 1432 patients aged 18 years and older who applied to the Internal Medicine outpatient clinic of Ordu University Training and Research Hospital between 01.01.2019 and 31.12.2019, and these patients had a chronic disease (diabetes mellitus, hypertension, thyroid diseases, heart disease, hyperlipidemia) were evaluated for vitamin $\mathrm{D}$ levels. The data of the patients were taken from the archive records retrospectively. Patients using vitamin $\mathrm{D}$ and immunosuppressive drugs, patients with primary hyperparathyroidism, patients receiving osteoporosis treatment, pregnant women, nursing mothers, patients with acute and chronic infections, patients with chronic kidney failure, patients using cigarettes and alcohol, patients with insufficient and incomplete archive data patients were not taken. Age, gender, existing chronic diseases and vitamin D levels of the patients were evaluated. Vitamin D levels were recorded at the first admission of patients who had more than one outpatient admission at the time the data of our study were collected. In our hospital, the vitamin $\mathrm{D}$ was studied as serum vitamin $\mathrm{D}$ level in Abbott Architect i2000-SR auto-analyzer. Patients with serum vitamin D level $<20 \mathrm{ng} / \mathrm{ml}$ were assigned to the vitamin $\mathrm{D}$ deficiency group; Patients with a range of $21-30 \mathrm{ng} / \mathrm{ml}$ were assigned to the vitamin $\mathrm{D}$ deficiency group; Patients with $>30 \mathrm{ng} / \mathrm{ml}$ were included in the normal vitamin $\mathrm{D}$ sufficiency group.

\section{Statistical Analysis}

All data were loaded into SPSS (Version 22.0, Inc., Illinois, Chicago, USA). In the evaluation of the data; number, percentage, mean and standard deviation were used for descriptive statistics. The distribution of data was evaluated with the Kolmogorov-Smirnow test. Student-T test was used to compare the groups. Pearson and Spearman tests were used for correlation analysis. A $P$ value less than 0.05 was considered significant.

\section{RESULTS}

In this study, 1432 patients whose vitamin D levels were measured from patients aged 18 years and older who applied to the Internal Medicine outpatient clinic were included. Of these patients, $23.6 \%(\mathrm{n}=340)$ were male and $76.4 \%(n=1092)$ were female. The mean age of the patients participating in the study; It was $36.22 \pm 13.46$ years. Average age of male patients; $38.43 \pm 12.51$ years, mean age of female patients; It was $34.63 \pm 14.32$ years. The number of patients diagnosed with vitamin $\mathrm{D}$ deficiency level $<20 \mathrm{ng} / \mathrm{ml}$ was 1090 (76.1\%); The number of patients diagnosed with vitamin $\mathrm{D}$ deficiency between $21-30 \mathrm{ng} / \mathrm{ml}$ was 176 (12.2\%); The number of patients with normal vitamin $\mathrm{D}$ with $>30$ $\mathrm{ng} / \mathrm{ml}$ was 166 (11.7\%). The mean serum vitamin D levels of the patients participating in the study were $14.28 \pm 13.61 \mathrm{ng} / \mathrm{ml}$. The mean serum vitamin D levels by gender are; It was found to be $15.3 \pm 11.7 \mathrm{ng} / \mathrm{ml}$ in women and $17.6 \pm 14.2 \mathrm{ng} / \mathrm{ml}$ in men. When we evaluate the relationship between the gender of the patients participating in the study and serum vitamin D levels; serum vitamin $\mathrm{D}$ levels in female patients were found to be significantly lower than in male patients $(\mathrm{p}=0.007)$ (Table 1).

\section{Table 1. Statistical comparison of the patients' genders and serum} vitamin D levels

\begin{tabular}{|c|c|c|c|c|c|c|c|}
\hline \multirow{3}{*}{$\begin{array}{l}\text { Serum } \\
\text { vitamin D } \\
\text { level }\end{array}$} & \multicolumn{4}{|c|}{ Gender } & \multirow{2}{*}{\multicolumn{2}{|c|}{ Total }} & \multirow{3}{*}{$\begin{array}{c}P \\
\text { value }\end{array}$} \\
\hline & \multicolumn{2}{|c|}{ Female } & \multicolumn{2}{|c|}{ Male } & & & \\
\hline & $\mathbf{n}$ & $\%$ & n & $\%$ & n & $\%$ & \\
\hline $\begin{array}{l}\text { Deficiency } \\
(<20 \mathrm{ng} / \mathrm{ml})\end{array}$ & 852 & 78.1 & 238 & 21.9 & 1090 & 100.0 & \\
\hline $\begin{array}{l}\text { Insufficiency } \\
(21-30 \mathrm{ng} / \mathrm{ml})\end{array}$ & 110 & 62.4 & 66 & 37.6 & 176 & 100.0 & 0.007 \\
\hline $\begin{array}{l}\text { Normal }(>30 \\
\mathrm{ng} / \mathrm{ml})\end{array}$ & 130 & 78.5 & 36 & 21.5 & 166 & 100.0 & \\
\hline
\end{tabular}

The median age of the patients participating in the study was calculated as 32 years. When we group our patients according to the age of 32 years; There was no statistically significant difference between the vitamin $\mathrm{D}$ levels of patients aged 32 years and younger and patients older than 32 years $(\mathrm{p}=0.214)$ (Table 2).

Significant differences were found between the groups in the statistical evaluation of the number of patients aged 18 years and older who were included in the study with a chronic disease (diabetes mellitus, hypertension, thyroid diseases, heart disease, hyperlipidemia) and their vitamin D levels $(\mathrm{p}=0.021, \mathrm{p}=0.012, \mathrm{p}=0.047, \mathrm{p}=0.043, \mathrm{p}=0.032$, respectively) (Table 3 ). 


\begin{tabular}{|c|c|c|c|c|c|c|c|c|c|}
\hline \multirow{3}{*}{ Age groups } & \multicolumn{6}{|c|}{ Serum vitamin D level } & \multirow{2}{*}{\multicolumn{2}{|c|}{ Total }} & \multirow{3}{*}{$P$ value } \\
\hline & \multicolumn{2}{|c|}{ Deficiency $(<20 \mathrm{ng} / \mathrm{ml})$} & \multicolumn{2}{|c|}{ Insufficiency $(21-30 \mathrm{ng} / \mathrm{ml})$} & \multicolumn{2}{|c|}{ Normal (>30 ng/ml) } & & & \\
\hline & $\mathbf{n}$ & $\%$ & $\mathbf{n}$ & $\%$ & $\mathbf{n}$ & $\%$ & $\mathbf{n}$ & $\%$ & \\
\hline$<32$ years & 532 & 73.6 & 92 & 12.6 & 98 & 13.5 & 722 & 100.0 & \multirow{2}{*}{0.214} \\
\hline$\geq 32$ years & 558 & 79.1 & 84 & 11.9 & 68 & 9.4 & 710 & 100.0 & \\
\hline
\end{tabular}

\begin{tabular}{l}
$\begin{array}{l}\text { Table 3. Statistical comparison of the number of patients with a chronic disease and vitamin D levels among the patients participating in the } \\
\text { study }\end{array}$ \\
\cline { 2 - 7 } Chronic Diseases
\end{tabular}

\section{DISCUSSION}

Vitamin D is a very important vitamin for bone metabolism. It is a necessary vitamin for both the normal development of the bone and the protection of the bone. Vitamin D deficiency or insufficiency has adverse effects on ossification of the cartilage matrix, osteoblastic activity, calcium and phosphorus metabolism, bone remodeling process, and bone density (14). In some studies, patients with a vitamin $\mathrm{D}$ threshold value of $<20 \mathrm{ng} / \mathrm{ml}$ were found to have vitamin $\mathrm{D}$ deficiency; When patients with a range of 21-30 ng/ml were accepted as vitamin D deficiency, an average of $75-92 \%$ of the patients were found to have vitamin D deficiency and insufficiency $(15,16)$. Erol and et al. (17) found the mean vitamin D level to be $10.6 \pm 6.5$ $\mathrm{ng} / \mathrm{ml}$ in their study and found the vitamin $\mathrm{D}$ level to be below $20 \mathrm{ng} / \mathrm{ml}$ in $92.2 \%$ of the patients. In our study, we found the mean serum vitamin $\mathrm{D}$ levels of the patients to be $14.28 \pm 13.61 \mathrm{ng} / \mathrm{ml}$, and we found the vitamin $\mathrm{D}$ level to be below $20 \mathrm{ng} / \mathrm{ml}$ in $76.1 \%$ of the patients. The reason why vitamin D level is so low in our country is; nutritional deficiencies, lifestyle and environmental factors play a role (18). In a study by Uçar and et al. (19), they found $51.8 \%$ of vitamin D deficiency and $20.7 \%$ of vitamin D deficiency. However, unlike our study, they did not find a difference between the sexes in terms of vitamin D levels. In our study, we found vitamin D deficiency and insufficiency in approximately $88.3 \%$ of patients aged 18 years and older who applied to our outpatient clinic in Ordu. In terms of gender, there were more vitamin D deficiency and insufficiency in the female patient group. In this case, Öğüs and et al. (20) found a higher rate of vitamin $\mathrm{D}$ deficiency and insufficiency in the female patient group than in the male patient group, similar to our study. The fact that more vitamin $\mathrm{D}$ deficiency has been detected in women can be attributed to the fact that women spend more time at home and as a result, they are not exposed to enough sun rays. In our study, we interpreted that the reason why vitamin D deficiency and insufficiency is so high in Ordu is the lack of exposure to sufficient sun rays due to the fact that the weather is cloudy and constantly rainy for most of the year due to weather conditions. However, in a study conducted in Asian societies where there is sufficient exposure to sunlight, vitamin D insufficiency and deficiency were also found. It has been shown that the reason for this is that exposure to sufficient sun rays is not sufficient for normal vitamin D levels, however, age factor, intake of foods containing sufficient calcium, amount of adipose tissue and adequate physical exercise have positive effects on vitamin D levels $(15,16)$.

Despite this, although adequate sun exposure has positive effects on vitamin D levels, there is a serious problem of vitamin D deficiency all over the world due to the harmful effects of long-term sun exposure and the increase in sun protection and the widespread use of sunscreens has occurred. In particular, Australia has become the country with the lowest vitamin D level due to the measures taken by the local people, such as using too much sunscreen and wearing long-sleeved clothes, due to the recent increase in skin cancers in Australia, where the sun's rays are sufficient (11). In a study conducted in Pakistan, a very high rate of vitamin $\mathrm{D}$ deficiency, such as $98.8 \%$, was found, and they attributed this to reasons such as insufficient exposure to sunlight, malnutrition, decreased 
physical activity and working in closed workplaces for a long time (21). Again, in a study conducted on patients with extensive bone and joint pain, vitamin $\mathrm{D}$ deficiency was found to be $71.1 \%$ (22). In our study, we found a high rate of vitamin $\mathrm{D}$ deficiency and insufficiency, such as $83.3 \%$. We thought that the reason for such high levels of vitamin $\mathrm{D}$ deficiency and insufficiency in our region may be due to inadequate sun exposure, closed dressing style, living in high altitude plateaus, low socioeconomic status, nutritional deficiency and decreased physical activity.

Vitamin D deficiency has been found to be associated with rickets in children, osteoporosis and osteomalacia in the elderly, cardiovascular diseases, diabetes mellitus, hyperlipidemia, thyroid diseases, some cancers, and many chronic diseases $(3,16)$. In particular, vitamin $\mathrm{D}$ has been shown to be an important determinant of mortality due to its anti-inflammatory, anti-oxidant and anti-ischemic properties $(12,13,23)$. In our study, there was a significant relationship between the patients with a chronic disease (diabetes mellitus, hypertension, thyroid diseases, heart disease, hyperlipidemia) and the vitamin $\mathrm{D}$ levels of the patients. Those with chronic disease had low vitamin D levels. In $75.4 \%$ of diabetes patients, $84 \%$ of hypertension patients, $60.6 \%$ of hypothyroid patients, $73.9 \%$ of patients with hyperthyroidism, $95.5 \%$ of patients with heart disease, and $84 \%$ of patients with hyperlipidemia, the vitamin $\mathrm{D}$ level was found to be below $30 \mathrm{ng} / \mathrm{ml}$ which is accepted as normal level. We believe that such a high rate of vitamin $\mathrm{D}$ deficiency and insufficiency in patients with chronic diseases is due to the lack of adequate and balanced nutrition in these patients, the negative effects of the drugs they use due to their diseases on vitamin D metabolism, decreased physical activity performance and not being exposed to adequate sunlight.

\section{CONCLUSION}

A high rate of vitamin D deficiency and insufficiency was detected in the patients who applied to our hospital, and considering that this situation would be related to dietary factors, insufficient sunlight exposure and insufficient exercise, it was suggested that adequate vitamin $D$ supplementation and dietary supplementation should be given to the patients. We think that awareness raising about exercise will have positive effects on the mortality of chronic diseases.

\section{ETHICAL DECLARATIONS}

Ethics Committee Approval: The study was carried out with the permission of Ordu University Clinical Research Ethics Committee (Date: 29.03.2018, Decision no: 2018-57).
Informed Consent: Because the study was designed retrospectively, no written informed consent form was obtained from patients.

Referee Evaluation Process: Externally peer-reviewed.

Conflict of Interest Statement: The author has no conflicts of interest to declare.

Financial Disclosure: The author declared that this study has received no financial support.

Author Contributions: All of the authors declare that they have all participated in the design, execution, and analysis of the paper, and that they have approved the final version.

\section{REFERENCES}

1. IOM (Institute of Medicine). Dietary reference intakes for calcium and vitamin D. Washington, DC: The National Academies Press; 2011.

2. Meer IM, Middelkoop BJC, Boeke AJP, et al. Prevalence of vitamin D deficiency among Turkish, Moroccan, Indian and sub-Sahara African populations in Europe and their countries of origin: an overview. Osteoporos Int 2011; 22: 1009-21.

3. Lips P. Vitamin D status and nutrition in Europe and Asia. J Steroid Biochem Molecul Biol 2007; 103: 620-5.

4. WHOQOL Group. The Development of the World Health Organisation quality of life assessment: International perspectives. Heidelberg: Springer Veriag 1994; 3: 41-57.

5. Champe PC, Harvey RA, Ferrier DR. Biyokimya. Çeviri Editörü: Ulukaya E. Lippincott's Illustrated Reviews Serisinden. 3. Bask1. Nobel Tip Kitapevleri. 2007.

6. Schoor MN, Lips P. Worldwide vitamin D status. Best Pract Res Clin Endocrinol Metab 2011; 25: 671-80.

7. Hekimsoy Z, Dinç G, Kafesçiler S, et al. Vitamin D status among adults in the Aegean region of Turkey. BMC Public Health 2010; 10: $782-8$.

8. Cannell JJ, Vieth R, Umhau JC, et al. Epidemic influenza and vitamin D. Epidemiol Infect 2006; 134: 1129-40.

9. Schottker B, Haug U, Schomburg L, et al. Strong associations of 25-hydroxyvitamin D concentrations with all-cause, cardiovascular, cancer, and respiratory disease mortality in a large cohort study. Am J Clin Nutr 2013; 97: 782-93.

10. Holick MF. Vitamin D: A millenium perspective. J Cell Biochem 2003; 88: 296-07.

11. Holick MF, Chen TC. Vitamin D deficiency: a worldwide problem with health consequences. Am J Clin Nutr 2008; 87: 1080-6.

12. Yap KS, Northcott $M$, Hoi AB, Morand EF, Nikpour $M$. Association of low vitamin $\mathrm{D}$ with high disease activity in an Australian systemic lupus erythematosus cohort. Lupus Sci Med 2015; $2: 64$

13. Lee IM, Shiroma EJ, Lobelo F, Puska P, Blair SN, Katzmarzyk PT. Effect of physical inactivity on major non-communicable diseases worldwide: an analysis of burden of disease and life expectancy. Lancet 2012; 380: 219-29.

14. Christodoulou S, Goula T, Ververidis A, Drosos G. Vitamin D and bone disease. Biomed Res Int 2013; 1: 1-6.

15. Kumar GT, Chugh R, Eggersdorfer M. Poor vitamin D status in healthy population in India: a review of current evidence. Int J Vitam Nutr Res 2015; 85: 1-7.

16. Atalay SG, Atalay R, Alkan BM, et al. Vitamin D deficiency in adults with musculoskeletal pain. Turk J Osteoporos 2015; 21: 101-4. 
17. Erol AM, Celik C, Hacioğlu K, et al. The relationship between vitamin D level and lipid profile in patients admitted to the Physical Medicine and Rehabilitation outpatient clinic. Ege Med J 2015; 54: 173-6.

18. Açıkgöz A, Günay T, Uçku R. Vitamin D requirements and supplementation during pregnancy. TAF Prevent Med Bull 2013; 12: 597-608.

19. Uçar F, Taşlıpınar MY, Soydaş AÖ, Özcan N. 25-OH Vitamin D levels in patients admitted to Ankara Etlik Training and Research Hospital. Eur J Basic Med Sci 2012; 2: 12-5.

20. Öğüş E, Sürer H, Kılınç AŞ, et al. Evaluation of Vitamin D levels by months, gender and age. Ankara Med J 2015; 15: 1-5.

21. Roomi MA, Farooq A, Ullah E, Lone KP. Hypovitaminosis D and its association with lifestyle factors. Pak J Med Sci 2015; 31: 1236 40.

22. Pearce SHS, Cheetham TD. Diagnosis and management of vitamin D deficiency. BMJ 2010; 340: 5664.

23. Chowdhury R, Kunutsor S, Vitezova A, et al. Vitamin D and risk of cause specific death: systematic review and meta-analysis of observational cohort and randomised intervention studies. BMJ 2014; 348: 1903. 